\title{
Opposing Effects of Glucagon and Triodothyronine on the Hepatic Levels of Messenger Ribonucleic Acid S14 and the Dependence of Such Effects on Circadian Factors
}

\author{
W. B. Kinlaw, H. L. Schwartz, H. C. Towle," and J. H. Oppenheimer \\ Division of Endocrinology and Metabolism, Department of Medicine, and *Department of Biochemistry, \\ University of Minnesota, Minneapolis, Minnesota 55455
}

\begin{abstract}
We have studied the effect of glucagon on the expression of a triiodothyronine (T3) and carbohydrate-inducible mRNA sequence (mRNA-S14) in rat liver that undergoes a threefold diurnal variation (peak, $2200 \mathrm{~h}$; nadir, $0800 \mathrm{~h}$ ). Glucagon injection into euthyroid rats $(25 \mu \mathrm{g} / 100 \mathrm{~g}$ body wt i.p., three doses at 15min intervals) during the nocturnal plateau of mRNA-S14 caused a monoexponential disappearance of this sequence $\left(t_{1 / 2}, 90 \mathrm{~min}\right)$ accompanied by a $90 \%$ reduction in the transcriptional rate in a nuclear run-off assay, indicative of a near total reduction of synthesis. This effect was markedly attenuated in rats treated with T3 (200 $\mu \mathrm{g} / 100 \mathrm{~g}$ body wt i.p.) $24 \mathrm{~h}$ before glucagon injection. When T3 was given 15 min after glucagon, the glucagon-initiated decline in mRNA-S14 was reversed within $90 \mathrm{~min}$, suggesting a rapid interaction between the two hormones in the evening. $\mathrm{Cu}$ riously, administration of $\mathrm{T} 3$ alone at this hour did not affect a significant increase in mRNA-S14. At $0800 \mathrm{~h}$, however, T3 caused the expected brisk induction of this sequence, whereas glucagon was without effect. In essence, glucagon affected mRNA-S14 synthesis only in the evening, while T3 increased levels of this sequence above the baseline only in the morning. T3, however, reversed the effect of prior glucagon injection at night. The observed alterations in hormonal responsivity could underly the diurnal variation of mRNA-S14 expression. Moreover, the data suggest the hypothesis that T3 may act on S14 gene expression by antagonizing factors that inhibit its transcription.
\end{abstract}

\section{Introduction}

Recent studies from our laboratory have focused on mRNAS14 as a model of thyroid hormone action at the hepatocellular level (1). This mRNA codes for a protein of relative molecular mass $\left(M_{\mathrm{r}}\right)^{1} 17,010$ and an isoelectric point $(\mathrm{pI})$ of 4.9 as first demonstrated in two-dimensional gel analysis of in vitro translation products in hepatic mRNA (2). Of particular interest is the rapid response of this sequence to triiodothyronine (T3) ad-

Address reprint requests to Dr. Kinlaw, University of Minnesota Hospitals, Box 91, Mayo Building, Minneapolis, MN 55455.

Received for publication 19 February 1986 and in revised form 15 May 1986.

1. Abbreviations used in this paper: ANOVA, analysis of variance; $M_{\mathrm{r}}$, relative molecular mass; $\mathrm{T} 3$, triiodothyronine.

J. Clin. Invest.

(c) The American Society for Clinical Investigation, Inc.

0021-9738/86/10/1091/06 \$1.00

Volume 78, October 1986, 1091-1096 ministration. The mature mRNA rises within $20 \mathrm{~min}$ and the nuclear RNA precursor within $10 \mathrm{~min}$ (3). Such findings provide considerable assurance that the effect of $\mathrm{T} 3$ on the $\mathrm{S} 14$ gene is direct and not mediated by the product of an antecedent T3 target gene. Of interest is the equally rapid response of the mature mRNA to the administration of dietary carbohydrate and the synergistic interaction between this dietary stimulus and T3 in the induction of mRNA-S14 (4). Such an interaction is typical of the behavior of several lipogenic enzymes previously studied in our laboratory (5). Another aspect of the regulation of hepatic mRNA-S14 is the threefold circadian variation in expression that has been demonstrated in the unmanipulated animal (1). These findings, together with the fact that mRNA-S14 is most abundantly expressed and regulated in lipogenic tissue (liver, lactating mammary gland, and adipose tissue) (6), suggest that this sequence encodes a protein involved in fatty acid synthesis. Towle and colleagues have sequenced the primary transcript of the S14 gene and have demonstrated the existence of two exons with one intervening sequence and the presence of two polyadenyation sites (7). No homology is apparent, either between the nucleotide sequence of the coding regions or the inferred amino acid sequence of the protein and corresponding sequences stored in national computer banks.

In an effort to identify the potential contribution of other factors that might be important in determining the expression of the S14 gene, we evaluated the effect of glucagon on mRNA$\mathrm{S} 14$ in the intact animal. This hormone was selected because several studies had previously demonstrated that glucagon inhibits the induction of mRNA for lipopogenic enzymes $(8,9)$, and studies by Mariash and co-workers in our laboratory had shown that glucagon causes a monoexponential decrement in the level of mRNA-S14 in cultured hepatocytes (10). The current report describes the results of our recent experiments in the living animal. The marked interaction of glucagon with T3 may provide an important clue regarding the molecular action of both hormones. Moreover, the exquisite dependence of both glucagon and $\mathrm{T} 3$ effects on circadian factors may reflect the operation of a hitherto unrecognized influence on the regulation of hepatic metabolism.

\section{Methods}

Animal manipulations. Male Sprague-Dawley rats (Biolab Corp., St. Paul, $\mathrm{MN}$ ) weighing $\sim 200 \mathrm{~g}$ (four per cage) were adapted to a 12-h light/12$\mathrm{h}$ dark (lights on at $0700 \mathrm{~h}$ ) schedule with ad lib. access to chow (Ralston Purina Co., St. Louis, MO) and water before use. Rats were killed (four per group) by exsanguination via the abdominal aorta under light ether anesthesia at the indicated intervals. Livers were frozen in liquid $\mathrm{N}_{2}$ and stored at $-80^{\circ} \mathrm{C}$. Hormone injections consisted of glucagon (Eli Lilly \& Co., Indianapolis, IN) in a $1: 4$ dilution of the diluent (glycerin $1.6 \%$, phenol $0.2 \%$ ) supplied by the manufacturer and given intraperitoneally 
in the doses and at the intervals indicated. Control animals received appropriate diluent alone. After preliminary dose-response studies, a regimen of three injections ( $25 \mu \mathrm{g}$ glucagon $/ 100 \mathrm{~g}$ body wt) at $15-\mathrm{min}$ intervals was employed routinely. T3 $(200 \mu \mathrm{g} / 100 \mathrm{~g}$ body wt) was given intraperitoneally in a solution of $2.5 \%$ human serum albumin at the indicated time before death. Experiments were performed during the morning $(0800 \mathrm{~h})$ or evening $(1700 \mathrm{~h})$ plateaus of the mRNA-S14 diurnal rhythm (1) to minimize fluctuations of the baseline.

Quantitation of $m R N A-S 14$. Quantitation was by dot-blot hybridization as previously described (1). Total hepatic RNA was extracted by a modification of the guanidine $\mathrm{HCl}$ method of Munnich et al. (11). Aliquots $(1,2,3,4 \mu \mathrm{g} / \mathrm{dot})$ of each sample were immobilized on nitrocellulose sheets (BA85; Schleicher and Schuell, Inc., Keene, NH) and hybridized in a solution of $\left.{ }^{32} \mathrm{P}\right] \mathrm{cDNA}-\mathrm{S} 14-\mathrm{E} 7,2 \times 10^{6} \mathrm{cpm} / \mathrm{ml}$ and $50 \%$ formamide at $42^{\circ} \mathrm{C}$ overnight. The insert, corresponding to $420 \mathrm{bp}$ of the $5^{\prime}$ coding region of mRNA-S14, was cloned by Dr. Towle (7). Quantitation was by computer-assisted videodensitometry (12) of autoradiographs prepared from the blots (AR5 x-ray film; Eastman Kodak Co., Rochester, NY). The relationship between autoradiographic OD and mass of RNA/dot was linear within the range employed. Results are expressed as OD per microgram RNA immobilized, determined by linear regression for each sample, as a percent of that observed for an interassay hepatic RNA standard pool derived from T3-treated, carbohydrate-fed rats.

Quantitation of the relative rate of S14 gene transcription. Quantitation was performed by the method of McKnight and Palmiter (13) using nuclei prepared by a modification of the method of Lamer (14), which has been published (15). The relative rate of $\mathrm{S} 14$ gene transcription, expressed as parts per million (ppm), was corrected for nonspecific binding to a filter on which plasmid (pBR322) DNA ( $2 \mu \mathrm{g}$ ) had been immobilized (5-10 ppm) and for the efficiency of the hybridization reaction (40-60\%) based on values obtained for a ${ }^{3} \mathrm{H}$-labeled cRNA synthesized from the S14 cDNA insert.

Two-dimensional electrophoresis of in vitro translation products. Electrophoresis was performed as described previously (2), employing a rabbit reticulocyte lysate system (Bethesda Research Laboratories, Gaithersburg, MD). $20 \mu \mathrm{g}$ of total RNA were added to each tube in the presence of $\left[{ }^{35} \mathrm{~S}\right]$ methionine (Amersham Corp., Arlington Heights, IL), and equal amounts $\left(1 \times 10^{6} \mathrm{cpm}\right)$ of TCA-precipitable radioactivity were subjected to two-dimensional electrophoresis by a modification of the procedure of O'Farrell (16). Quantitation of autoradiographic spots that appeared to change on all gels by visual inspection was by the videodensitometric method of Mariash et al. (12). These data were transformed $(\ln [x+1])$ before statistical analysis.

All results were assessed by analysis of variance (ANOVA) (17) or linear regression as indicated in the text.

\section{Results}

Initially we assessed the effect of intraperitoneal injections of glucagon on the hepatic level of mRNA-S14. These experiments were carried out in the evening (1900-2400 h) when the hepatic content of mRNA-S14 is maximal (1). Rats (four per group) received either vehicle or glucagon $(2.5$ or $25 \mu \mathrm{g} / 100 \mathrm{~g}$ body wt i.p.) starting at $1930 \mathrm{~h}$, and all animals were killed at $2400 \mathrm{~h}$. A significant $(P<0.05)$ diminution of mRNA-S14 below the levels of unmanipulated animals was observed with both doses of glucagon $(2.5 \mu \mathrm{g} ; 28 \pm 3 \%$ of unmanipulated (mean \pm SEM, $25 \mu \mathrm{g}$; $16 \pm 4 \%)$. Since the vehicle-injected groups also revealed a significant $(P<0.05)$ but lesser decrement $(50 \pm 9 \%)$ in comparison to the unmanipulated animals, it was apparent that vehicle administration also constituted a stimulus for the reduction of mRNA-S14. In another set of experiments with a different injection schedule (one injection at $1900 \mathrm{~h}$, one at $1945 \mathrm{~h}$; animals killed at $2030 \mathrm{~h}$ ), we also noted a dose-response relationship. Glucagon doses of 25,50 , and $100 \mu \mathrm{g} / 100 \mathrm{~g}$ body wt lowered
mRNA-S14 levels to $48 \pm 7,31 \pm 6$, and $20 \pm 2 \%$ of the initial value, respectively.

We examined in greater detail the apparently nonspecific effect produced by vehicle injections. We considered the possibility that this effect could have resulted from one of two factors: (a) the light exposure that was necessitated by the experimental manipulation during the dark cycle of the animals, or $(b)$ the cessation of food intake that we noted in injected animals. Accordingly, the following experiment was performed. Separate groups of rats were exposed to (a) $4 \mathrm{~h}$ of light, (b) $4 \mathrm{~h}$ of food restriction, and $(c)$ light exposure and vehicle injection every 40 min. The latter group failed to consume chow during the experiment. Results are depicted in Table I. Food deprivation per se resulted in a $54 \%(P<0.05)$ reduction in the level of mRNAS14. Light exposure by itself, however, was without effect. The combined effects of repeated injections, the resultant voluntary food deprivation, and light exposure closely approximated the reduction produced by food restriction alone. We could not test the effect of injections independent of food restriction, since, as pointed out above, the injected animals stopped eating. In preliminary experiments, however, sucrose gavage ( $1 \mathrm{ml} \mathrm{60 \% /100}$ $\mathrm{g}$ body $\mathrm{wt}$ ) before vehicle injections abrogated the nonspecific effect (data not shown). Our findings are therefore consistent with the hypothesis that the effects of vehicle injections result from the cessation of food intake that accompanies injections.

The observation that administration of glucagon results in a marked and immediate depression of mRNA-S14 raised the question of the specificity of this effect for this mRNA sequence. Accordingly, we compared the translational activity profile of hepatic RNA obtained from control, vehicle, and glucagontreated animals. Such profiles were generated by two-dimensional electrophoretic separation of radioactively labeled in vitro translational products. The intensity of the spots generated by radioautography was quantitated by computer-assisted densitometry. Visual inspection of the $\sim 240$ spots seen on the gels showed that only the translational product of mRNA-S14 decreased in intensity over the $4 \mathrm{~h}$ after either glucagon or vehicle injection (Table II). Although the mean intensity of spot 14 diminished in the vehicle-injected animals, the decrease did not reach statistical significance. Of interest was the observation that two hitherto unrecognized spots, $\left(M_{\mathrm{r}} / \mathrm{pI}, 38,000 / 6.6 ; 52,000 / 6.6\right)$ in-

Table I. Effects of Food Restriction, Light Exposure, and Vehicle Injection on Hepatic mRNA-S14

\begin{tabular}{lllll}
\hline Treatment & & & & Chow \\
Injection & Food & Light & & $\begin{array}{l}\text { mRNA- } \\
\text { consumed }\end{array}$ \\
\hline & & & g/4 rats per $4 h$ & $\%$ basal \\
No & Yes & Off & 21 & $100 \pm 4$ \\
No & Yes & On & 29 & $105 \pm 15$ \\
No & No & Off & 0 & $46 \pm 8^{*}$ \\
Yes & Yes & On & 0 & $50 \pm 9^{*}$ \\
& & & & \\
\hline
\end{tabular}

Rats (four per group) were subjected to either food restriction, exposure to light, or both, with or without diluent injection every $\mathbf{4 0 ~ m i n}$ from 1930 to $2400 \mathrm{~h}$. The effect of injection and normal food intake could not be assessed, as injected animals did not eat offered chow. Hepatic mRNA-S14 is expressed as a percentage (mean \pm SEM) of the mean level in the basal state (food present, lights off) at $2400 \mathrm{~h}$.

* Different from basal, $P<0.05$ by ANOVA. 
Table II. Rapid Effects of Repeated Glucagon Injection on Translational Activities of Rat Hepatic mRNAs

\begin{tabular}{llcc}
\hline & \multicolumn{2}{l}{ Translational Products } \\
\cline { 2 - 4 } Group & S14 & GLUC 1 & GLUC 2 \\
\hline & $c p m / s p o t$ & $c p m / s p o t$ & $c p m / s p o t$ \\
Unmanipulated & $959 \pm 292$ & 0 & 0 \\
$\begin{array}{l}\text { Diluent } \\
\begin{array}{l}\text { Glucagon }(25 \mu \mathrm{g} / 100 \mathrm{~g} \\
\text { body wt) }\end{array}\end{array}$ & $510 \pm 152$ & $36 \pm 15$ & $312 \pm 78^{*} \ddagger$ \\
\hline
\end{tabular}

Data are mean \pm SEM (three per group). Glucagon-inducible spots are identified GLUC 1 or $2\left(M_{\mathrm{r}} / \mathrm{pI}, 52,000 / 6.6,38,000 / 6.6\right.$, respectively). Animals were killed at $2400 \mathrm{~h}$ after $4.5 \mathrm{~h}$ of injections at 40 -min intervals. Data were transformed $[\ln (x+1)]$ for statistical analysis.

* Different from unmanipulated, $P<0.05$ by ANOVA.

$\ddagger$ Different from vehicle injected, $P<0.05$.

creased after both vehicle and glucagon administration. For each, the increase was significantly greater with glucagon. Our results therefore indicate that the rapid effects of glucagon on levels of specific mRNA sequences are highly selective. It is conceivable, however, that those mRNA sequences that diminished within the 4-h experimental period had rapid fractional turnover and that other sequences with longer half-times would have also changed if the stimulus had been maintained for a longer period. Further, our results support our supposition that the glucagoninduced changes are qualitatively similar to those brought about by vehicle injection, presumably as a consequence of the associated cessation of food intake.

As illustrated in Fig. 1, we examined in greater detail the kinetics of decline of mRNA-S14 as a consequence of a series of three intraperitoneal glucagon doses $(25 \mu \mathrm{g} / 100 \mathrm{~g}$ body wt administered at 15 -min intervals). These experiments started at $1900 \mathrm{~h}$ and terminated $4 \mathrm{~h}$ later. Euthyroid rats demonstrated a monoexponential decline in mRNA-S14 $(r=-0.86)$ to $18 \%$ of the initial value at $4 \mathrm{~h}$. In the same experiment, we tested the effect of T3 $(200 \mu \mathrm{g} / 100 \mathrm{~g}$ body wt, i.p.) administered $24 \mathrm{~h}$ before glucagon (Fig. 1). In this group, the effect of glucagon was markedly attenuated; levels of mRNA-S14 fell only to $70 \%$ of the baseline value.

The monoexponential disappearance of mRNA-S14 after glucagon injection in euthyroid animals suggested that this effect could be the result of a cessation of transcription. A large increase in the fractional degradation rate of mRNA-S14, however, could lead to a similar result that could not be readily differentiated given the inherent experimental variation. We therefore tested this question directly by nuclear run-off assay in euthyroid and hyperthyroid rats before and $105 \mathrm{~min}$ after glucagon injection. In euthyroid rats, the transcriptional rate declined by over $90 \%$ after glucagon ( $218 \pm 15$ to $17 \pm 3$ ppm, mean \pm SD). Hyperthyroid animals exhibited only a $19 \%$ diminution $(228 \pm 24$ to $185 \pm 24$ ppm). Given the variance associated with both the kinetic and transcriptional measurements, it appeared that the reduced transcriptional rate accounted for most, if not all, of the difference between the initial value and the new steady state in the hyperthyroid group.

It appeared possible that the ability of $\mathrm{T} 3$ to partially reverse the effect of glucagon was the result of a lowered glucagon concentration caused by a T3-induced increase in glucagon turnover.

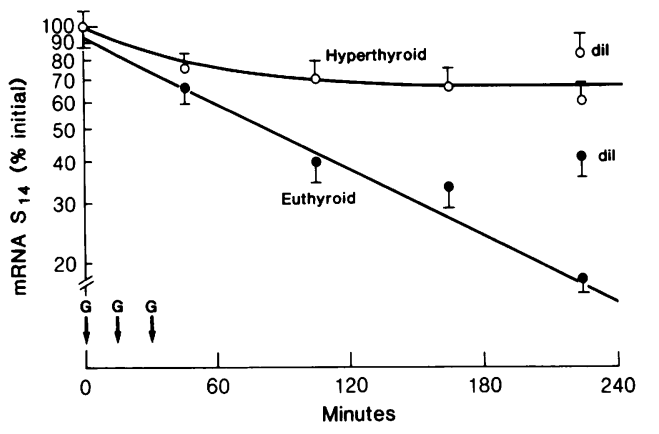

Figure 1. Time course of mRNA-S14 disappearance after glucagon injection. Rats received either T3 $(200 \mu \mathrm{g} / 100 \mathrm{~g}$ body wt, i.p.) or saline $18 \mathrm{~h}$ before glucagon injection $(25 \mu \mathrm{g} / 100 \mathrm{~g}$ body wt, i.p., three doses at 15 -min intervals) at $1900 \mathrm{~h}$. Animals (8 per timepoint) were killed 4 $h$ after glucagon injection. Data are percent of initial (mean \pm SEM); dil, groups that received diluent rather than glucagon; arrows, time of glucagon injection. The plot for the hyperthyroid group is depicted as curvilinear because in vitro nuclear transcriptional assays demonstrated a submaximal (20\%) diminution in this group, in contrast to the essentially complete $(90 \%)$ reduction in the euthyroid group.

An increased turnover of many substances is associated with the hyperthyroid state produced by $\mathrm{T} 3$. This appeared possible in our protocol because T3 was fully administered $1 \mathrm{~d}$ before glucagon. To evaluate this possibility, we injected T3 $(200 \mu \mathrm{g} /$ $100 \mathrm{~g}$ body wt i.p.) $15 \mathrm{~min}$ after the initial series of three glucagon injections $(25 \mu \mathrm{g} / 100 \mathrm{~g}$ body wt every $15 \mathrm{~min})$. Animals were killed 90 min after the T3 injection $(2115 \mathrm{~h})$. Fig. $2 A$ shows an almost immediate reversal of the glucagon-induced decline in mRNA-S14. Since the full metabolic effects of T3 are not achieved until many hours after T3 administration (18), these observations made it improbable that the glucagon level was lowered as a consequence of a T3-induced increase in glucagon turnover. Of interest in this experiment was the surprising observation that animals injected with T3 alone at this hour (1900) showed no increase in mRNA-S14 over baseline levels. This stands in contrast with the brisk increase in MRNA-S14 observed in animals injected with T3 in the morning (19). The failure of $\mathrm{T} 3$ to elicit a major increase in the level of mRNA-S14 when injected in the evening was confirmed in a longer experiment in which $\mathrm{T} 3(200 \mu \mathrm{g} / 100 \mathrm{~g}$ body wt) was administered to a group of four euthyroid rats at $1900 \mathrm{~h} .4 \mathrm{~h}$ later, only a nonsignificant $25 \pm 7 \%$ (mean \pm SEM) increase was observed.

To complement studies of the interaction of glucagon and T3 in the evening, we carried out an analogous protocol in the morning, when the level of mRNA-S14 is one-third of that at $1900 \mathrm{~h}$ (Fig. 2 B). As expected from previous studies, T3 administration resulted in a 2.3 -fold increase in the level of mRNA$\mathrm{S} 14$ within $90 \mathrm{~min}$. Curiously, however, glucagon did not cause a further lowering of the basal value of mRNA-S14 and had no effect on the induction of this sequence by subsequent treatment with T3.

\section{Discussion}

One of the basic findings in this study is the prompt reduction in the level of mRNA-S14 when glucagon is administered to euthyroid rats in the evening. After preliminary studies in which we examined several injection schedules, we standardized our approach by injecting three successive doses of glucagon $(25 \mu \mathrm{g} /$ 

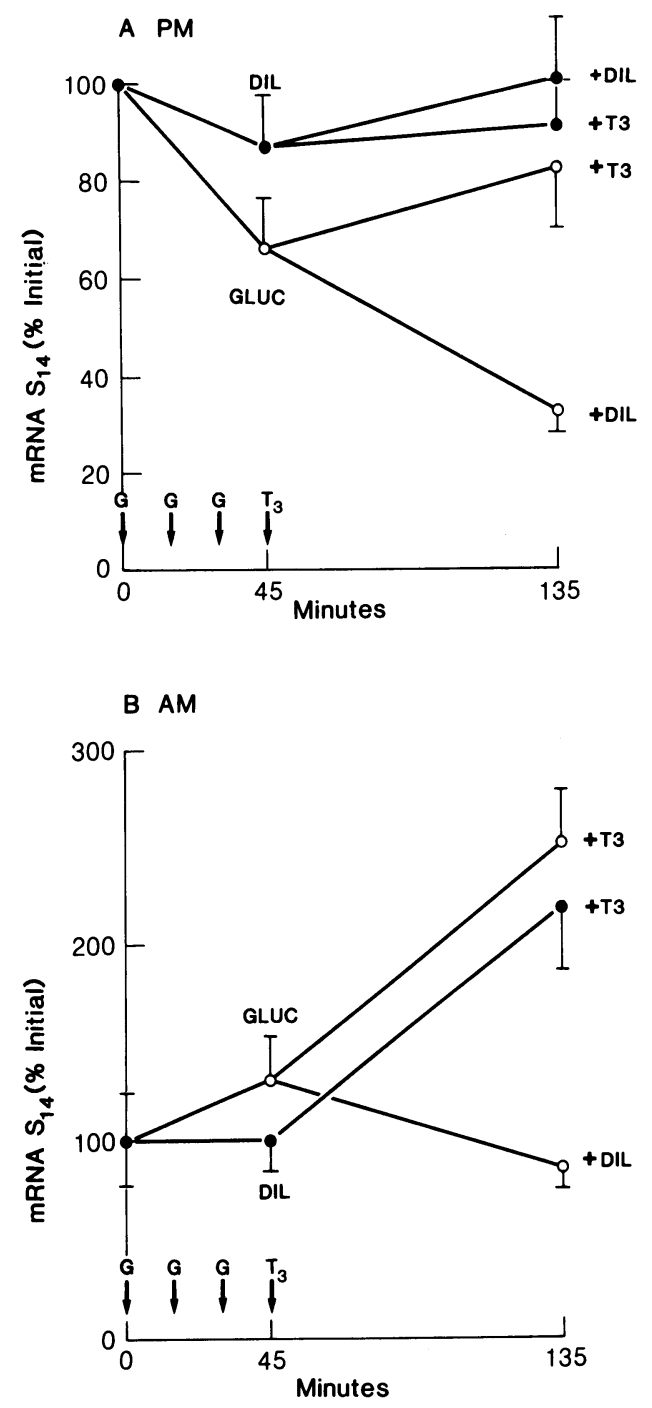

Figure 2. Rapid interaction of $\mathrm{T} 3$ and glucagon at the peak (PM) and nadir (AM) of the mRNA-S14 diurnal cycle. Data are mean \pm SEM (eight per timepoint). Rats received diluent or glucagon $(25 \mu \mathrm{g} / 100 \mathrm{~g}$ body wt i.p., three doses at 15 -min intervals), followed 15 min later by diluent or T3 ( $200 \mu \mathrm{g} / 100 \mathrm{~g}$ body wt i.p.). GLUC $+\mathrm{T} 3$ indicates $\mathrm{T} 3$ after glucagon, Dil $+\mathrm{T} 3$ indicates T3 following diluent, GLUC + dil received no T3. AM panel commenced at $0800 \mathrm{~h}, \mathrm{PM}$ at $1900 \mathrm{~h}$.

$100 \mathrm{~g}$ body wt) at 15 -min intervals. This resulted in a monoexponential disappearance of mRNA-S14 for the subsequent $4 \mathrm{~h}$ with an approximate $t_{1 / 2}$ of $90 \mathrm{~min}$. The fact that during this period the disappearance curve did not trail off suggested that the mechanism responsible for the decay was a cessation in the formation of the mRNA, either because of an interruption of transcription, a defect in nuclear processing, or destabilization of the precursor mRNA (3). Transcriptional assays indicated a $90 \%$ reduction in in vitro nuclear transcription rates after glucagon injection. If we assume that these measurements provide a valid indication of in vivo processes and that glucagon has no additional effects on the turnover of mRNA-S14, we can infer, from the kinetic data, an approximate half-life for mRNA-S14 of $90 \mathrm{~min}$.

The effect of glucagon on mRNA-S14 levels within the time period studied appeared to be highly selective. Visual examination of two-dimensional mRNA activity profiles revealed that of the 240 spots visible, mRNA-S14 was the only sequence that decreased as a result of glucagon administration. Two other mRNA sequences, however, increased. The electrophoretic mobility of one of these spots $\left(M_{\mathrm{r}}, 38,000\right)$ did correspond to the enzyme tyrosine aminotransferase, which is known to be induced by glucagon (20). The mobility of the other spot $\left(M_{\mathrm{r}}, 52,000\right)$ did not correspond to that of other known glucagon-inducible mRNA sequences, such as that encoding phosphoenolpyruvate carboxykinase (21). It is probable, however, that if we had extended the duration of our studies, we would have been able to demonstrate the increase or decrease of other $\mathrm{mRNA}$ sequences. A half-time of $\sim 90$ min allows mRNA-S14 to fluctuate rapidly under the influence of a variety of stimuli.

Of interest was the observation that repeated injections of vehicle resulted in a reproducible decrease in mRNA-S14. This decrease, however, was uniformly less than that produced by glucagon. Further, our studies indicate that animals subjected to injection stopped eating and that the decrement of mRNAS14 in food-restricted rats over a similar time period was almost identical to that in injected rats. Moreover, preliminary studies indicate that sucrose gavage prevents this effect. We therefore believe that the nonspecific effects of vehicle injection that we observed can be explained by the cessation of food intake, although the possibility that both reduced food intake and mRNAS14 reduction are due to a common stress-related stimulus cannot be rigorously excluded. The increase in the two mRNA sequences noted in the mRNA activity profile after vehicle injection may therefore also represent the effects of food deprivation. The fact that levels of the same mRNA sequences are influenced both by glucagon and vehicle injection suggests that the effects of glucagon on mRNA levels are qualitatively similar but of greater magnitude than those initiated by food deprivation.

A second major finding in these studies was that T3 antagonizes the effect of glucagon on mRNA-S14. When animals were treated with a receptor-saturating dose of $\mathrm{T} 31 \mathrm{~d}$ before glucagon injection, only a $31 \%$ decrement in mRNA-S14 was observed. Moreover, there was a preservation of the nuclear transcription rate in the T3-treated group. The lesser decrement in mRNAS14 levels appears to reflect a transcriptional effect rather than a stabilization of the mRNA by T3 under these circumstances. Of additional interest is the speed with which $\mathrm{T} 3$ antagonizes the glucagon effect. In the experiment illustrated in Fig. $2 \mathrm{~A}$, the injection of $\mathrm{T} 3$ was followed by a reversal of the glucagon effect within $90 \mathrm{~min}$. It is therefore apparent that the ability of T3 to reverse the effect of glucagon is not contingent on the establishment of a hyperthyroid state in the tissues, since this requires many hours (18).

Previous studies in our laboratory have led to the proposal that there is a multiplicative interaction between the T3 nuclear receptor complex and a factor induced by carbohydrate metabolism in the induction of several lipogenic enzymes. Such interactions have been observed both in the intact animal (5) as well as in cultured hepatocytes (22). More recent experiments have shown that there is a similar synergistic interaction between carbohydrate and T3 in the induction of mRNA-S14 (4). The resemblance between the behavior of lipogenic enzymes and mRNA-S14 is in accord with the current evidence favoring a role for the S14 protein in lipogenesis, as cited in the introduction. In hepatocyte culture studies, the addition of glucagon causes a rapid decrease in mRNA-S14 but, curiously, this effect is not antagonized by the presence of $\mathrm{T} 3(10)$. These findings point to a significant difference between the in vitro and in vivo systems, which thus far remains unexplained. 
Most unanticipated was the third major finding, namely the dependence of the hepatic response to T3 and glucagon on circadian factors. When glucagon was administered at $0800 \mathrm{~h}$, there was no fall in mRNA-S14, in marked and reproducible contrast to the brisk reduction affected at $1900 \mathrm{~h}$. On the other hand, in confirmation of multiple previous studies from our laboratory, T3 elicited the expected 2.3-fold increase in mRNA-S14 when injected into euthyroid rats at $0800 \mathrm{~h}$. Further, glucagon was unable to antagonize this response. These changes in hepatic responsivity were reminiscent of the threefold circadian variation in mRNA-S14 that we have previously studied (1). In unmanipulated animals feeding ad libitum and with a 0700-1900-h lights on period, the nadir of hepatic mRNA-S14 occurs at $\sim 1000 \mathrm{~h}$ and the zenith at $\sim 2200 \mathrm{~h}$.

It appears possible that the circadian variation in levels of mRNA-S14 is a reflection of the changes in sensitivity to the stimuli noted in the present studies. We should like to advance an admittedly speculative hypothesis to account for such changes. We propose that a circulating inhibitor of mRNA-S14 formation, analogous to glucagon, undergoes periodic cycles with maximal values in the morning and minimal values in the evening. Such a factor would account for the minimal values of the mRNA in the morning and the maximal values in the evening. Administration of glucagon in the morning produces no further effect, as inhibition is already maximal. Further, we propose that T3 serves to antagonize the effect of this inhibitor, thus allowing a major increase in the rate of mRNA production after administration of $\mathrm{T} 3$ in the morning. In the evening, the endogenous rate of production of mRNA-S14 is maximal, since the inhibitor is minimal. Injection of T3 therefore produces no further increase in the level of mRNA-S14. Glucagon, however, inhibits the generation of mRNA-S14, resulting in the observed decrease. Provision of an exogenous inhibitor at that hour permits the demonstration of a T3 effect that is not otherwise observed. It should be possible to test this hypothesis in further experiments. Of interest in this regard is the report of Tiedgen and Seitz (23) that circulating levels of glucagon in rats on a stock diet resembling our own exhibit a vary small diurnal variation that is not reflected in hepatic cAMP content. It therefore appears unlikely that glucagon itself is the putative circadian inhibitory factor.

The broader physiological significance of these findings deserves comment. We recognize that the doses of glucagon used in these studies, though commonly used in whole animal experiments, may be supraphysiologic. Although it is tempting to suggest that the elevations of glucagon associated with starvation (24) may contribute to the reduction of mRNA-S14 in that circumstance, the precise role of glucagon in this and other processes must await a rigorous quantitative comparison of plasma levels and tissue effects. On the other hand, our results do suggest that glucagon could serve as a physiological inhibitor of S14 gene transcription. If the circadian factors noted in these experiments also influence the generation of mRNA sequences coding for lipogenic enzymes, the longer half-lives of such sequences will obscure the effect on levels of those sequences. The results of our studies may also have implications with respect to $\mathrm{T} 3$ action at the molecular level. The observation that $\mathrm{T} 3$ rapidly overrides the inhibitory influence of glucagon raises the possibility that thyroid hormone may act by opposing factors that inhibit the transcription of other genes as well. Such a proposal, however, poses a dilemma. If glucagon reduces mRNA-S14 expression by inhibiting transcription and T3 reverses this process, we would anticipate that the administration of $\mathrm{T} 3$ to hypothyroid animals should result in augmented transcription. Studies by Narayan and Towle (15), however, have shown that the increase in the in vitro nuclear transcriptional assay is modest and transient, and is clearly insufficient to account for the observed increase in mRNA-S14 induced by T3. This discrepancy, in conjunction with the kinetic data showing that the nuclear precursor of mRNA-S14 rises before the mature RNA, prompted these authors to propose that the stabilization of the precursor was a major contributory factor to the observed increase in the mature RNA. Three potential explanations arise. (a) The glucagon-T3 interaction may be only a special example and not a general model of thyroid hormone action. (b) The in vivo inhibitory factor may be better preserved in nuclei derived from hypothyroid animals, thus leading to an underestimation of the transcriptional component in the induction of mRNA-S14 by T3 in hypothyroid animals. (c) Glucagon destabilizes the primary transcript both in vivo and in the in vitro nuclear assay. This would lead both to a reduction in the formation rate of the mature RNA in vivo and to an apparent reduction in the in vitro transcriptional assay. Again, we would have to postulate that the glucagon effect would carry over more effectively from the in vivo to the in vitro assay than the effect of hypothyroidism. Other explanations could be advanced, but additional data are required to resolve the issue.

\section{Acknowledgments}

We thank B. Gunville, A. Martinez-Tapp, M. E. Domeier, and D. Iden for expert technical assistance; K. Steinmeyer for manuscript preparation; and $P$. Schaus for administrative services.

This work was supported by National Institutes of Health grants AM-01277 (Dr. Kinlaw), AM-19812 (Dr. Oppenheimer), and AM-26919 (Dr. Towle).

\section{References}

1. Jump, D. B., P. Narayan, H. Towle, and J. H. Oppenheimer. 1983. Rapid effects of triiodothyronine on hepatic gene expression: hybridization analysis of tissue-specific triiodothyronine regulation of mRNA-S14. J. Biol. Chem. 259:2789-2797.

2. Seelig, S., C. Liaw, H. C. Towle, and J. H. Oppenheimer. 1981. Thyroid hormone attenuates and augments hepatic gene expression at a pretranslational level. Proc. Natl. Acad. Sci. USA. 78:4733-4737.

3. Narayan, P., C. W. Liaw, and H. C. Towle. 1984. Rapid induction of a specific nuclear mRNA precursor by thyroid hormone. Proc. Natl. Acad. Sci. USA. 81:4687-4691.

4. Mariash, C. N., S. A. Seelig, H. L. Schwartz, and J. H. Oppenheimer. 1986. Rapid synergistic interaction between thyroid hormone and carbohydrate on mRNA-S14 induction. J. Biol. Chem. 261:95839586.

5. Mariash, C. N., F. E. Kaiser, H. L. Schwartz, H. C. Towle, and J. H. Oppenheimer. 1980. Synergism of thyroid hormone and high carbohydrate diet in the induction of lipogenic enzymes in the rat. J. Clin. Invest. 65:1126-1134.

6. Jump, D. B., and J. H. Oppenheimer. 1985. High basal expression and 3-5-3'-triiodothyronine regulation of messenger ribonucleic acid S14 in lipogenic tissues. Endocrinology. 1117:2259-2266.

7. Liaw, C., and H. C. Towle. 1984. Characterization of a thyroid hormone-responsive gene from the rat. J. Biol. Chem. 259:7253-7260.

8. Winberry, L. K., S. M. Morris, Jr., J. E. Fisch, M. J. Glymas, R. A. Jenik, and A. G. Goodridge. 1983. Molecular cloning of cDNA sequences for avian malic enzyme. J. Biol. Chem. 258:1337-1342.

9. Siddiqui, V. A., T. Goldflam, and A. G. Goodridge. 1981. Nutritional and hormonal regulation of the translatable levels of malic enzyme 
and albumin mRNA in avian liver cells in vivo and in culture. J. Biol. Chem. 256:4544-4550.

10. Mariash, C. N., D. B. Jump, and J. H. Oppenheimer. 1984. T3 stimulates the synthesis of a specific mRNA in primary hepatocyte culture. Biochem. Biophys. Res. Commun. 123:1122-1129.

11. Munnich, A., D. Daegelen, C. Besmond, J. Marie, J. C. Dreyfus, and A. Kahn. 1982. Cell-free translation of messenger RNA's from human muscle biopsies: a miniaturized tool for investigation of neuromuscular diseases. Pediatr. Res. 16:335.

12. Mariash, C. N., S. Seelig, and J. H. Oppenheimer. 1982. A rapid, inexpensive quantitative technique for the analysis of two-dimensional electrophoretograms. Anal. Biochem. 121:388-394.

13. McKnight, G. S., and R. D. Palmiter. 1979. Transcriptional regulation of the ovalbumin and conalbumin genes by steroid hormones in chick oviduct. J. Biol. Chem. 257:2133-2136.

14. Lamers, W. H., R. W. Hanson, and H. M. Meisner. 1982. cAMP stimulates transcription of the gene for cytosolic phosphoenolpyruvate carboxykinase in rat liver. Proc. Natl. Acad. Sci. USA. 79:5137-5141.

15. Narayan, P., and H. C. Towle. 1985. Stabilization of a specific nuclear mRNA precursor by thyroid hormone. Mol. Cell. Biol. 5:26422646.

16. O'Farrell, P. H. 1975. High resolution two-dimensional electrophoresis of proteins. J. Biol. Chem. 10:4007-4021.

17. Snedecor, G. W., and W. G. Cochran. 1980. Statistical Methods. Iowa State University Press, Ames, Iowa. 54.
18. Tata, J. R. 1962. Intracellular and extracellular mechanisms for the utilization and action of thyroid hormones. Recent Prog. Horm. Res. 18:221.

19. Seelig, S., D. B. Jump, H. C. Towle, C. Liaw, C. N. Mariash H. L. Schwartz, and J. H. Oppenheimer. 1982. Paradoxical effects of cycloheximide on the ultra-rapid induction of two hepatic mRNA sequences by triiodothyronine (T3). Endocrinology. 110:671-673.

20. Hargrove, J. L., M. Diesterhalt, T. Noguchi, and D. K. Granner. 1979. Identification of native tyrosine aminotransferase and an explanation for the multiple forms. J. Biol. Chem. 255:71-78.

21. Ballard, F. J., and R. W. Hanson. 1969. Purification of phosphoenolpyruvate carboxykinase from the cytosol fraction of rat liver and the immunochemical demonstration of differences between this enzyme and mitochondrial phosphoenolpyruvate carboxykinase. J. Biol. Chem. 244:5625-5630.

22. Mariash, C. N., and J. H. Oppenheimer. 1984. Stimulation of malic enzyme formation in hepatocyte culture by metabolites: evidence favoring a nonglycolytic metabolite as the proximate induction signal. Metab. Clin. Exp. 32:545-552.

23. Teidgen, M., and H. J. Seitz. 1980. Dietary control of circadian variations in serum insulin, glucagon, and cyclic AMP. J. Nutr. 110: 876-882.

24. Srikant, C. B., D. Freeman, K. McCorkle, and R. H. Unger. 1977. Binding and biologic activity of glucagon in liver cell membranes of chronically hyperglucagonemic rats. J. Biol. Chem. 252:7434-7436. 